\title{
Functional differentiation of RAMP2 and RAMP3 in their regulation of the vascular system
}

Akihiro Yamauchi, Takayuki Sakurai, Akiko Kamiyoshi, Yuka Ichikawa-Shindo, Hisaka Kawate, Kyoko Igarashi, Yuichi Toriyama, Megumu Tanaka, Tian Liu, Xian Xian, Akira Imai, Liuyu Zhai, Shinji Owa, Takuma Arai, Takayuki Shindo*

Department of Cardiovascular Disease, Shinshu University Graduate School of Medicine, Japan

\section{A R T I C L E I N F O}

\section{Article history:}

Received 11 June 2014

Received in revised form 12 September 2014

Accepted 15 September 2014

Available online 28 September 2014

\section{Keywords:}

Receptor activity-modifying protein (RAMP)

Adrenomedullin (AM)

Knockout mice

Angiogenesis

Lymphatic drainage

\begin{abstract}
A B S T R A C T
Adrenomedullin (AM) is a vasoactive peptide that possesses various bioactivities. AM receptors are dimers consisting of CLR with one of two accessory proteins, RAMP2 or RAMP3. The functional difference between CLR/RAMP2 and CLR/RAMP3 and the relationship between the two receptors remain unclear. To address these issues, we generated RAMP2 and RAMP3 knockout (-/-) mice and have been studying their physiological activities in the vascular system. AM - / - and RAMP2 - / - mice die in utero due to blood vessel abnormalities, which is indicative of their essential roles in vascular development. In contrast, RAMP3 - / - mice were born normally without any major abnormalities. In adult RAMP3-/ - mice, postnatal angiogenesis was normal, but lymphangiography using indocyanine green (ICG) showed delayed drainage of subcutaneous lymphatic vessels. Moreover, chyle transport by intestinal lymphatics was delayed in RAMP3-/ - mice, which also showed more severe interstitial edema than wild-type mice in a tail lymphedema model, with characteristic dilatation of lymphatic capillaries and accumulation of inflammatory cells. In scratch-wound assays, migration of isolated RAMP3-/ - lymphatic endothelial cells was delayed as compared to wild-type cells, and AM administration failed to enhance the re-endothelialization. The delay in re-endothelialization was due to a primary migration defect rather than a decrease in proliferation. These results suggest that RAMP3 regulates drainage through lymphatic vessels, and that the AM-RAMP3 system could be a novel therapeutic target for controlling postoperative lymphedema.
\end{abstract}

c 2014 Elsevier Ltd. All rights reserved.

\section{Introduction}

Vascular homeostasis is regulated primarily by humoral factors and their receptor systems. For example, blood and lymphatic vessels secrete a number of bioactive molecules that possess systemic, paracrine and autocrine activities. Among these vasoactive mediators, adrenomedullin (AM) is a 52-amino acid peptide first isolated from human pheochromocytoma [1]. Although named for the adrenal medulla and first identified as a vasodilator, we and others have shown that AM is secreted by numerous other tissues and organs, and that it exerts a variety of effects, including diuretic [2] and cardiotonic

Abbreviations: AM, adrenomedullin; CLR, calcitonin receptor-like receptor; RAMP, receptor activity-modifying protein; GPCR, G protein-coupled receptor; CGRP, calcitonin gene-related peptide; DI-VE-RAMP2-/-, drug-inducible vascular endothelial cellspecific RAMP2-/-; DI-LE-RAMP2-/-, drug-inducible lymphatic endothelial cellspecific RAMP2-/-; Cre-ERT2, tamoxifen-inducible Cre-recombinase; LDPI, laser Doppler perfusion imaging; ICG, indocyanine green; WT, wild-type.

* Corresponding author at: Department of Cardiovascular Disease, Shinshu University Graduate School of Medicine, Asahi 3-1-1, Matsumoto, Nagano 390-8621, Japan. Tel.: +8126337 2578; fax: +81263373437.

E-mail address: tshindo@shinshu-u.ac.jp (T. Shindo).
[3] effects, and is involved in the regulation of hormone release [4,5], inflammation [6], oxidative stress [7,8], and the proliferation, migration and differentiation of various cell types [9-11]. Thus, AM is now known to be a pleiotropic bioactive substance.

Adrenomedullin is a member of the calcitonin superfamily and acts via calcitonin receptor-like receptor (CLR), a seven transmembrane G protein-coupled receptor (GPCR) [12]. The ligand specificity of CLR is dependent on its association with a set of accessory proteins called receptor activity-modifying proteins (RAMPs), which contain a singletransmembrane domain and three $\alpha$-helix structures in their extracellular domain. Three RAMP subtypes (RAMP1-3) have been identified, which show about $30 \%$ homology to one another [13]. By interacting with RAMP1, CLR acquires a high affinity for calcitonin gene-related peptide (CGRP), whereas interaction with either RAMP2 or RAMP3 gives CLR a high affinity for AM [12-15]. We previously showed that homozygous AM or RAMP2 knockout (AM-/ - or RAMP2-/-) mice die in utero due to edema and hemorrhage related to abnormal angiogenesis [16,17]. More recently, we developed drug-inducible vascular endothelial cell-specific RAMP2-/ - (DI-VE-RAMP2-/-) mice, with which we can induce RAMP2 gene deletion in adults. Using this model, we found that RAMP2 is essential for angiogenesis and vascular 
homeostasis in adults, as DI-VE-RAMP2-/- mice exhibit vascular structural abnormalities and spontaneously develop vascular inflammation and organ fibrosis [18]. Collectively, these findings indicate that the AM-RAMP2 system is essential for angiogenesis and vascular homeostasis throughout a mouse's life, from embryo to adult. Interestingly, in both RAMP2-/ - and DI-VE-RAMP2-/ - mice, we detected no compensatory upregulation of other RAMPs, which indicates a lack of redundancy among the functions of RAMP isoforms. In particular, the function of RAMP3, which also gives CLR a high affinity for AM, remains almost unknown.

Our aim was to clarify the functional differences between RAMP2 and RAMP3 in the vascular system. We focused particularly on the function of RAMP3 in the present study. To accomplish this, we generated RAMP3 $-/-$ mice and compared their phenotype with those of RAMP2 $+/-$, DI-VE-RAMP2 $-/-$, and drug-inducible lymphatic endothelial cell-specific RAMP2-/ - (DI-LE-RAMP2-/-) mice.

\section{Materials and methods}

\subsection{Animals}

RAMP2 - / - and RAMP3 - / - mice were generated by our group [17]. Tamoxifen-sensitive DI-VE-RAMP2-/ - and DI-LE-RAMP2-/mice were generated by crossbreeding floxed RAMP2 mice (RAMP2flox/flox) with mice expressing tamoxifen-inducible Crerecombinase (Cre-ERT2) under regulation of the VE-cadherin promoter (VE-cadherin-CreERT2) and the Prox-1 promoter (Prox1-CreERT2), respectively. Tamoxifen (Sigma) was dissolved in corn oil (Sigma) to a

Table 1

Primers and probes used for RT-PCR and quantitative real-time RT-PCR

\begin{tabular}{|c|c|}
\hline \multicolumn{2}{|c|}{ Primers and probes used for quantitative real-time RT-PCR } \\
\hline AM forward & CTACCGCCAGAGCATGAACC \\
\hline AM reverse & GAAATGTGCAGGTCCCGAA \\
\hline AM probe & CCCGCAGCAATGGATGCCG \\
\hline CLR forward & AGGCGTTTACCTGCACACACT \\
\hline CLR reverse & CAGGAAGCAGAGGAAACCCC \\
\hline CLR probe & ATCGTGGTGGCTGTGTTTGCGGAG \\
\hline RAMP1 forward & GCACTGGTGGTCTGGAGGA \\
\hline RAMP1 reverse & СССТCATCACCTGGGATACCT \\
\hline RAMP1 probe & CAAGCGCACAGAGGGCATCGTG \\
\hline RAMP2 forward & GCAGCCCACCTTCTCTGATC \\
\hline RAMP2 reverse & AACGGGATGAGGCAGATGG \\
\hline RAMP2 probe & CCCAGAGGATGTGCTCCTGGCCAT \\
\hline RAMP3 forward & TGCAACGAGACAGGGATGC \\
\hline RAMP3 reverse & GCATCATGTCAGCGAAGGC \\
\hline RAMP3 probe & AGAGGCTGCCTCGCTGTGGGAA \\
\hline VEGF-A forward & CATCTTCAAGCCGTCCTGTGT \\
\hline VEGF-A reverse & CTCCAGGGCTTCATCGTTACA \\
\hline CD31 forward & CTGCAGGCATCGGCAAA \\
\hline CD31 reverse & GCATTTCGCACACCTGGAT \\
\hline Podoplanin forward & TGGCAAGGCACCTCTGGTA \\
\hline Podoplanin reverse & TGAGGTGGACAGTTCCTCTAAGG \\
\hline LYVE-1 forward & AAGCAGCTGGGTTTGGAGGT \\
\hline LYVE-1 reverse & CACCAAAGAAGAGGAGAGCCA \\
\hline VEGF-C forward & ССТСТСТСACAAGGCCCCA \\
\hline VEGF-C reverse & TAGACATGCACCGGCAGGA \\
\hline VEGF-R3 forward & AAGGCCTGCCCATGCA \\
\hline VEGF-R3 reverse & TCGCCAGGGTCCATGATG \\
\hline \multicolumn{2}{|c|}{ Primers used for RT-PCR } \\
\hline AM forward & TCGAATTCATCGCCACAGAATGAAGCTGGT \\
\hline AM reverse & TCGAATTCTATATCCTAAAGAGTCTGGAGA \\
\hline CLR forward & ACAGCACGCATGAGAAAGTG \\
\hline CLR reverse & CCCTTGCATGTCACTGATTG \\
\hline RAMP1 forward & CTGCTGGCTCACCATCTCTT \\
\hline RAMP1 reverse & TCTTTTAATCACAAACTGTGCATC \\
\hline RAMP2 forward & CATCCCACTGAGGACAGCCT \\
\hline RAMP2 reverse & GATCATGGCCAGGAGCACAT \\
\hline RAMP3 forward & TCCACAGGCAGTTCTTTTCC \\
\hline RAMP3 reverse & CCTCTCTGGCCAAGTGTGAGC \\
\hline
\end{tabular}

concentration of $10 \mathrm{mg} / \mathrm{ml}$, after which $40 \mathrm{mg} / \mathrm{kg}$ and $80 \mathrm{mg} / \mathrm{kg}$ were intraperitoneally injected daily for 5 days into male DI-VE-RAMP2 -/ - and DI-LE-RAMP2-/ - mice, respectively.

All animal handling procedures were performed in accordance with a protocol approved by the Ethics Committee of Shinshu University. Before the operative procedures, mice were anesthetized by intraperitoneal injection of 2,2,2-tribromoethanol ( $240 \mathrm{mg} / \mathrm{kg}$; Wako, Osaka, Japan).

\subsection{Tumor implantation model}

Sarcoma 180 (S180) murine transplantable tumor cells were transplanted subcutaneously into the bilateral axillae of each mouse at a dose of $1 \times 10^{7}$ cells in $0.1 \mathrm{ml}$ of vehicle. On day 14 after tumor transplantation, laser Doppler perfusion imaging (LDPI) (Omegazone, Omegawave, Inc., Tokyo, Japan) was used to evaluate tumoral blood flow before the tumors were removed for analysis.

\subsection{Unilateral hind-limb ischemia model}

RAMP3 - / - mice and their controls were subjected to experimentally induced hind-limb ischemia produced by unilateral occlusion of the femoral artery, as described previously [19]. LDPI was used to evaluate the blood flow. The calculated perfusion was expressed as a ratio of the left (ischemic) to the right (normal) limb. Capillary density was assessed in the limbs 35 days after surgery by immunostaining of CD31.

\subsection{Analysis of subcutaneous lymphatic drainage}

To analyze ear subcutaneous lymphatic vessels, one ear was intradermally injected with $5 \mu \mathrm{l}$ of indocyanine green (ICG) (Daiichi-Sankyo, Tokyo, Japan) at the edge of the ear using a Hamilton syringe. To analyze tail lymphatic vessels, the tail of the anesthetized mouse was injected intradermally with $10 \mu \mathrm{l}$ of ICG at a site $3 \mathrm{~cm}$ from the base of the tail. Images were then taken using a Heidelberg Retina Angiograph 2 (Heidelberg Engineering $\mathrm{GmbH}$, Germany) $15 \mathrm{~min}$ and 60 min after the ear and tail injections, respectively.

\subsection{Evaluation of intestinal lymphatic vessels}

HFD32 (Clea Japan, Inc.), a high-fat mouse food containing 32\% fat, was dissolved in an equal volume of water. Mice were administered $0.3 \mathrm{~g}$ of the HFD32 using a feeding tube. Six hours or 2 days after feeding, the mice were anesthetized, after which an incision was made in the abdomen, and the mesentery was drawn out. About $15 \mathrm{~cm}$ from the pylorus, the intestinal lymphatic vessel within the mesentery was photographed. In addition, histological analysis was performed using the intestine collected $6 \mathrm{~h}$ after the HFD feeding.

\subsection{Tail lymphedema model}

Tail lymphedema was induced as described previously with modification [20]. In brief, a 3-mm-wide ring of skin was then removed $1 \mathrm{~cm}$ distal to the base of the tail, leaving the underlying bone, muscles and major blood vessels intact. The injured region of the tail was then wrapped with adhesive tape to protect the surgical site from infection,

Table 2

Genotypes of offspring from RAMP3 +/ - intercrosses. RAMP3 +/+, RAMP3 +/ - and RAMP3 - / - mice were born normally at a ratio consistent with Mendel's laws.

\begin{tabular}{|c|c|c|c|}
\hline & WT & Hetero & Homo \\
\hline & RAMP3 +/+ & RAMP3 +/- & RAMP3 $-/-$ \\
\hline No. of $\sigma^{7}$ & 29 & 61 & 24 \\
\hline No. of 우 & 24 & 43 & 23 \\
\hline Total no. & 53 & 104 & 47 \\
\hline Ratio & 1.00 & 1.96 & 0.89 \\
\hline
\end{tabular}



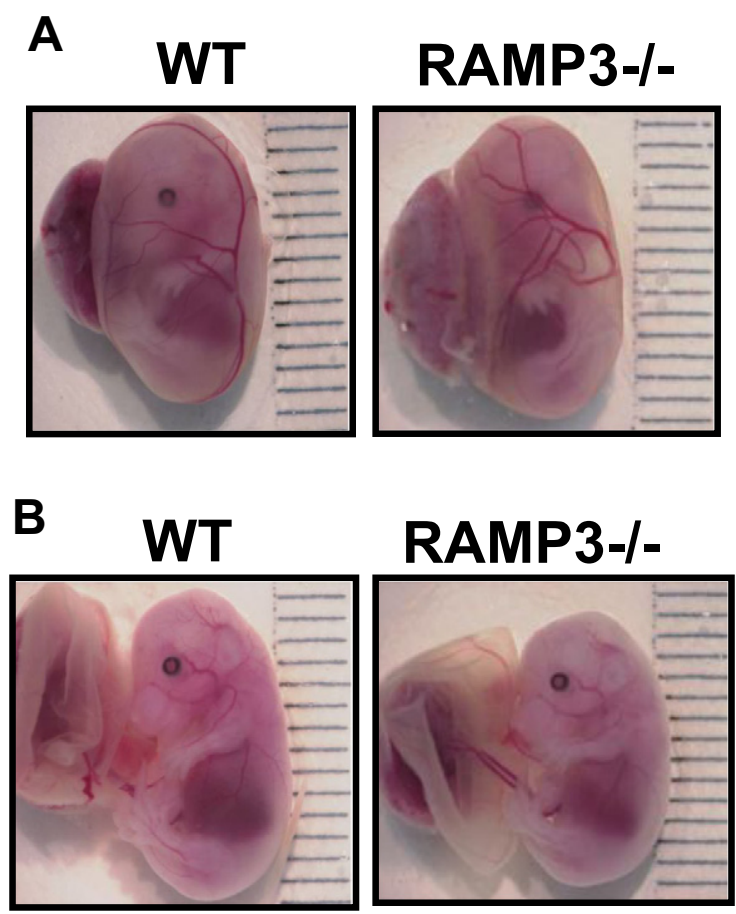

C

WT

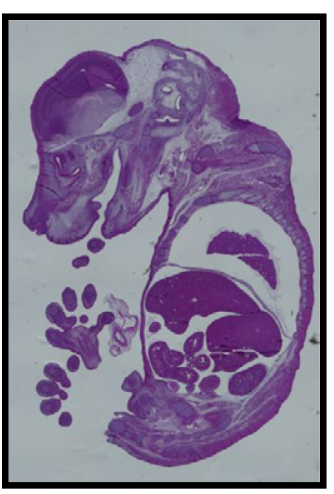

RAMP3-/-

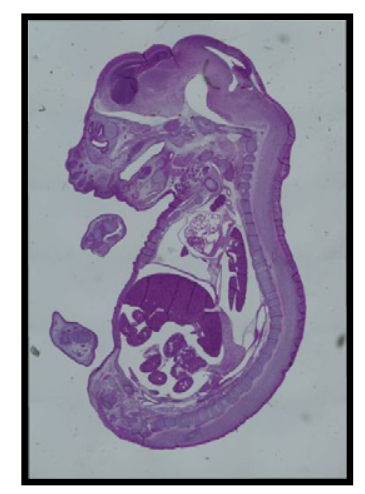

Fig 1. Observation of embryos and vascular development. WT and RAMP3 - - E14.5 embryos were examined. (A) Appearance of the yolk sac. (B) Appearance of the embryo with placenta, yolk sac and umbilical cord. (C) H\&E staining of a section of embryo. Unlike AM $-/-$ and RAMP2 - / - embryos, which die in utero due to vascular abnormalities, RAMP3-/ - embryos were apparently normal.
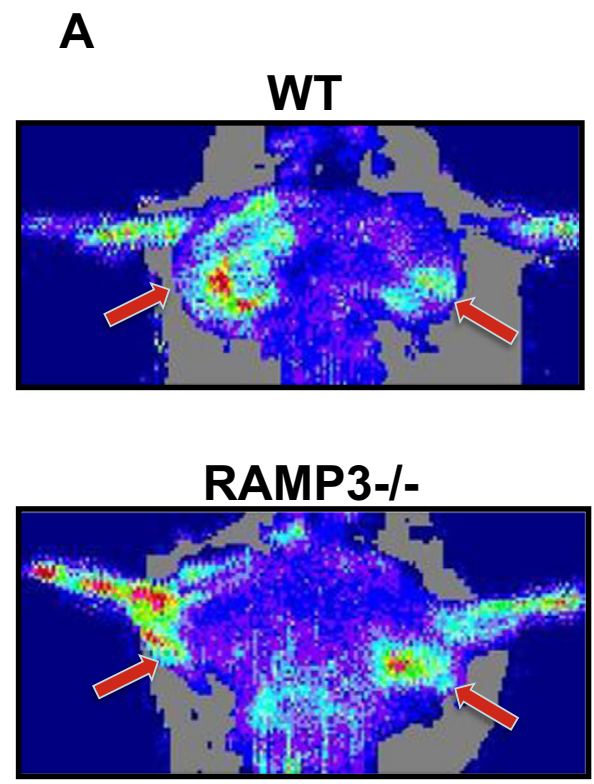
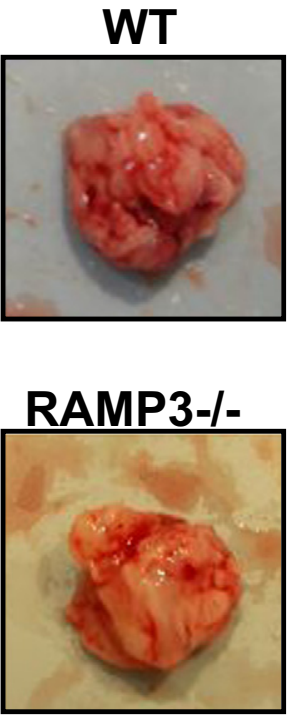

B
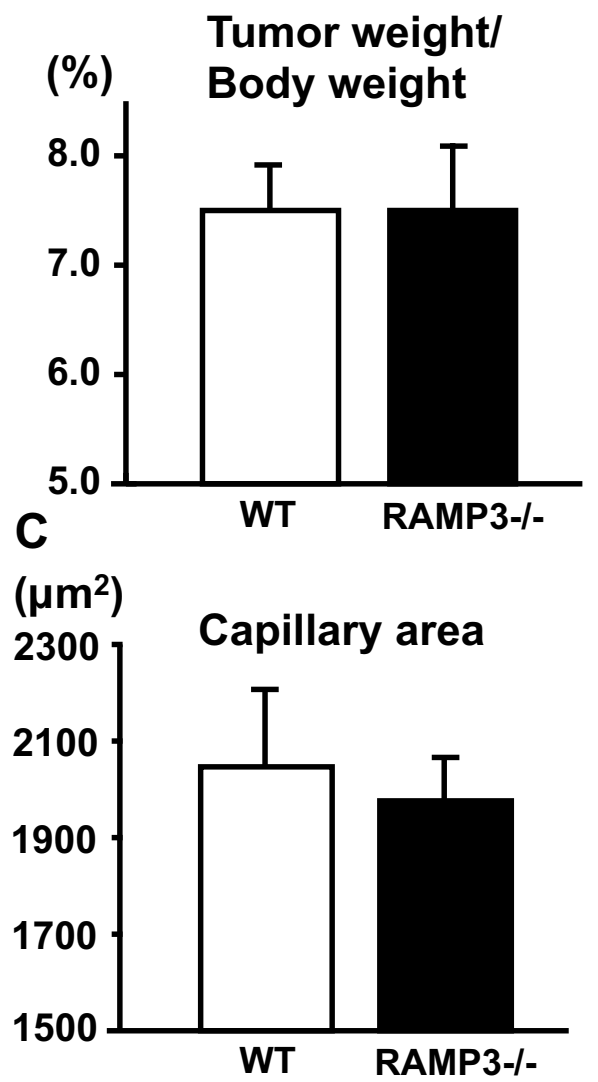

Fig. 2. Evaluation of tumor angiogenesis. S180 cells were transplanted subcutaneously into the bilateral axillae of mice. (A) Laser Doppler perfusion image of the tumors (left panels) and the appearance of the tumors (right panels) resected from WT and RAMP3-/ - mice 14 days after transplantation. Arrows indicate the tumor transplantation site. (B) Comparison of tumor weight/body weight ratios. (C) Comparison of intratumor capillary areas, which are expressed per microscopic field $(200 \times)$. $\mathrm{n}=8$ for both WT and RAMP3 $-/-$. Bars are the mean \pm SEM. Neither tumor weight nor tumor angiogenesis differed between WT and RAMP3 $-/-$ mice. 
and the tail diameter was measured $1 \mathrm{~cm}$ from the distal edge of the injury. For pathology and gene expression analysis, a $0.5 \mathrm{~cm}$ length of tail extending from the distal edge of the injury was collected.

\subsection{Histology}

Tissues were fixed overnight in $4 \%$ paraformaldehyde, embedded in paraffin, and cut into 5 - $\mu \mathrm{m}$-thick sections for histological examination. The specimens were then deparaffinized for hematoxylin/eosin (H\&E) staining, toluidine blue staining (Wako, Osaka, Japan) and immunohistochemistry using anti-CD45 (BD Biosciences), anti-CD31 (BD Biosciences) and anti-LYVE-1 antibodies (Relia Tech $\mathrm{GmbH}$ ). Nuclei were stained using DAPI (Life Technologies). Fluorescence was observed using a fluorescence microscope equipped with the appropriate filter sets (BZ-900, KEYENCE, Osaka, Japan). Toluidine blue at pH 2.5 was used to stain mast cells.

\subsection{Transmission electron microscopy}

Specimens were fixed in 2.5\% glutaraldehyde ( $\mathrm{pH} 7.2$ ), embedded in epoxy resin (Epok) 812 (Oken Shoji Co.), cut into ultrathin sections, double-stained with uranyl acetate and lead citrate, and examined with an electron microscope.

\subsection{Collection and culture of lymphatic endothelial cells}

Lymphatic endothelial cells were isolated from E16.5 WT and RAMP3 - / - embryos and cultured in EGM-2-MV medium (Lonza) as described by Kazenwadel et al. [21]. The cells were cultured with a mixture of growth factors supplied by the manufacturer (SingleQuots Kit, catalog No. CC4147, Lonza). We confirmed that more than 90\% of cells were LYVE-1-positive lymphatic endothelial cells. Cells passaged up to four times were used for experimentation.

\subsection{Scratch-wound assay}

To assess the proliferation and migration of isolated lymphatic endothelial cells, we performed scratch-wound assays according to the method of Liang et al. [22], with some modifications. Lymphatic endothelial cells were grown until $90 \%$ confluence in $3.5-\mathrm{cm}$ dishes with EGM-2-MV medium. One hour before the start of the assay, the medium was changed to EGM-2-MV with or without growth factors added to the product by the supplier. The center of the culture dish was then scratched using a P200 pipet tip, washed 2 times with the medium, and the culture was continued for $6 \mathrm{~h}$ in EGM-2-MV with or without growth factors. The effect of AM $\left(10^{-7} \mathrm{M}\right)$ was assayed in the absence of growth factors. Four images of the scratched areas per dish were captured using a light microscope (Olympus, Tokyo, Japan). The cell-
A
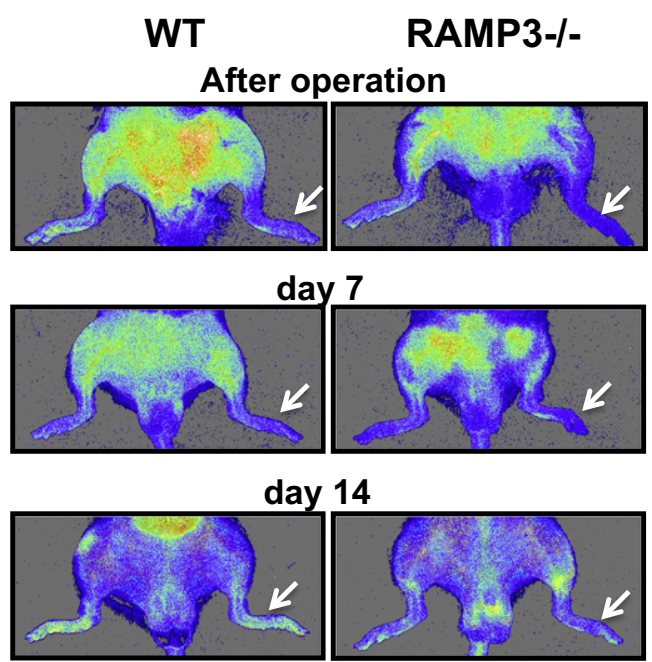

day 21
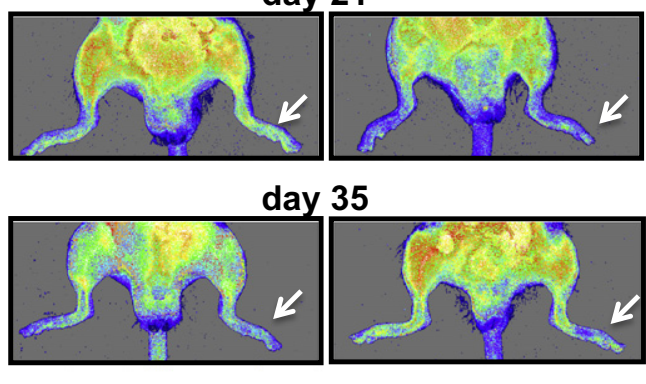

$\left.\int_{500}\right]_{1000}^{(R U)}$
B
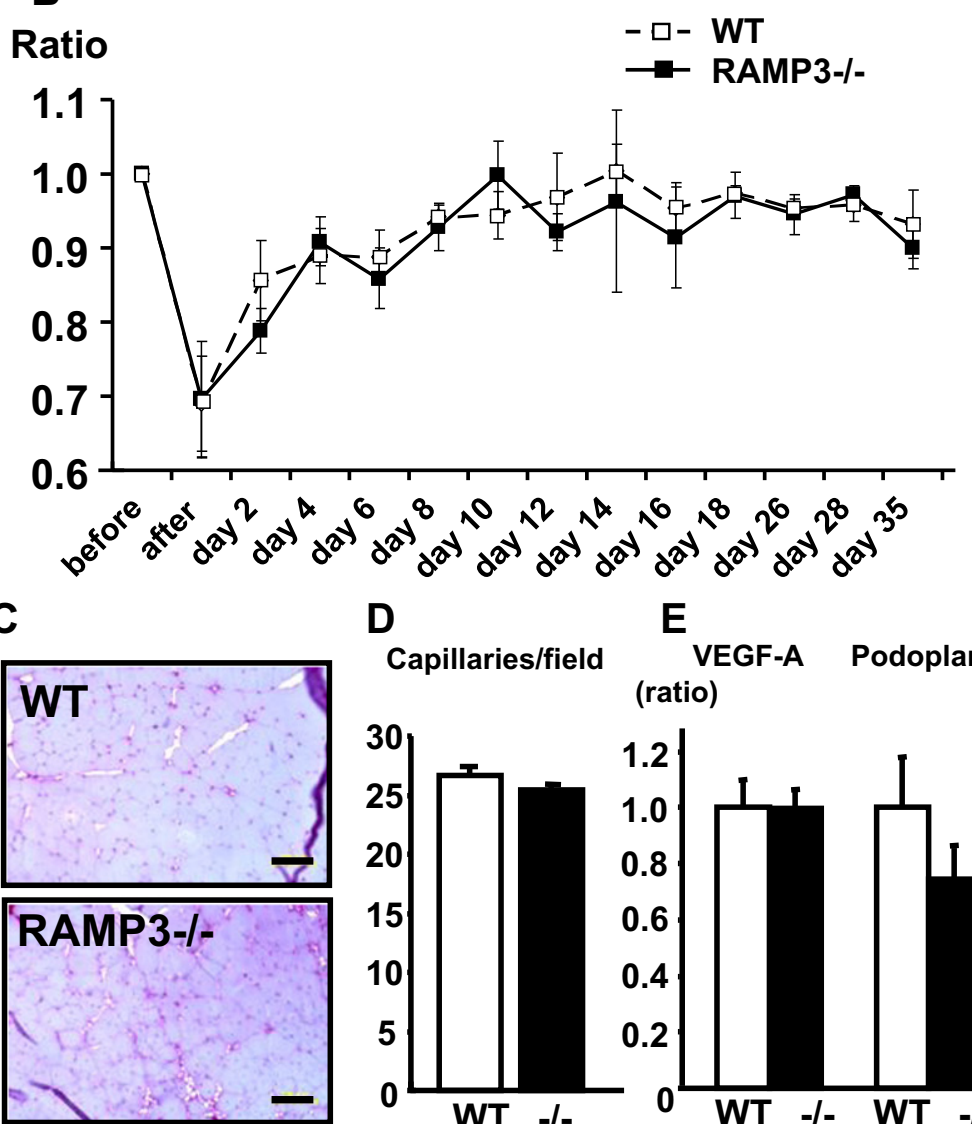

Capillaries/field

VEGF-A Podoplanin (ratio)

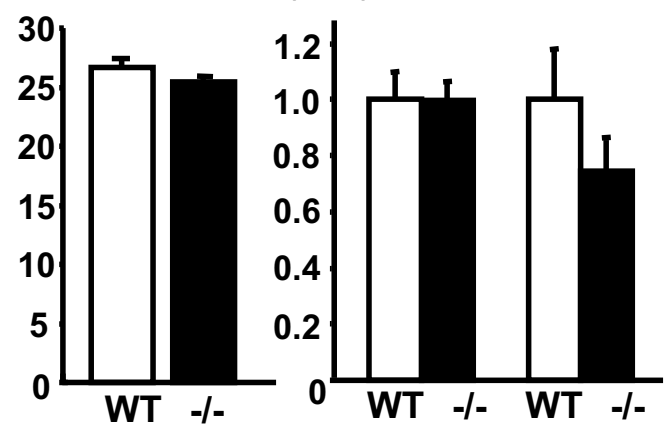

Fig. 3. Evaluation of ischemia-induced angiogenesis in the unilateral hind-limb ischemia model. (A) Laser Doppler perfusion image showing recovery of blood perfusion in the ischemic hind-limb (arrows). (B) Blood flow is expressed as a ratio of the left (ischemic) to the right (normal) limb. $\mathrm{n}=8$ in both WT and RAMP3-/-. Symbols are mean \pm SEM. (C) Sections showing the neovascularization (CD31 immunostaining) of the femoral muscle. Scale bars $=100 \mu \mathrm{m}$. (D) Comparison of the capillary density in the ischemic muscle 35 days after surgery. Capillary number per microscopic field $(400 \times)$ is shown. $n=8$ in both WT and RAMP3 $-/-$. (E) Quantitative real-time PCR analysis of femoral muscle 35 days after surgery. $\mathrm{n}=5$ in both WT and RAMP3 $-/-$. Bars are mean \pm SEM. In the hind-limb ischemia model, blood flow recovery, neovascularization and VEGF-A expression were all comparable between WT and RAMP3-/- mice. 
covered area was determined as a percentage of the cell-free area at $0 \mathrm{~h}$ measured in four fields per well using cellSens software (Olympus). The experiment was repeated three times on separate occasions.

\subsection{RNA extraction and quantitative real-time RT-PCR analysis}

Total RNA was extracted from tissues using TRI Reagent (Molecular Research Center, Inc.), after which the RNA was treated with DNAFree (Ambion) to remove contaminating DNA and reverse transcribed using a High Capacity cDNA Reverse Transcription Kit (Applied Biosystems). Quantitative real-time RT-PCR was carried out using an Applied Biosystems 7300 real-time PCR System with SYBR green (Toyobo, Japan) or Realtime PCR Master Mix (Toyobo) and TaqMan probes (MBL, Japan). The primers and probes used are listed in Table 1. Values were normalized to mouse GAPDH (Pre-Developed TaqMan assay reagents, Applied Biosystems).

\subsection{Western blot analysis}

Lymphatic endothelial cells were cultured without growth factors for $1 \mathrm{~h}$ and then stimulated with AM $\left(10^{-7} \mathrm{M}\right)$. Western blot analysis was carried out using protein extracts from lymphatic endothelial cells. The lysates were subjected to electrophoresis using TGX gel (Bio-Rad Laboratories), transferred to PVDF membranes (Bio-Rad Laboratories), and probed using anti-Akt, anti-phospho-Akt (P-Akt) antibodies (Cell Signaling). Anti- $\beta$-tubulin antibody (Santa Cruz Biotechnology) served as a loading control. The blots were then developed using an ImageQuant LAS 4000 (GE Healthcare).

\subsection{Statistical analysis}

Values are expressed as the mean \pm SEM. Student's $t$ test and the Mann-Whitney U test were used to evaluate differences between two groups. Values of $\mathrm{P}<0.05$ were considered significant.

\section{Results}

\subsection{RAMP3 - / - mice show normal vascular development}

We initially analyzed the genotypic distribution of the offspring from intercrosses within heterozygous RAMP3 knockout mice (RAMP3 $+/-$ ). As shown in Table 2 , the rates of RAMP3 $+/+$ RAMP3 + / - and RAMP3 - / - offspring were consistent with Mendel's law (the $+/+:+/-:-/-$ ratio was approximately $1: 2: 1$ ). Furthermore, we detected no abnormalities in RAMP3 - / - embryos at mid-gestation (Figs. 1A-C). Unlike AM-/ - and RAMP2-/ - embryos, both of which show poor development of vitelline vessels on the yolk sac and systemic edema with hemorrhage, vascular development appeared normal in RAMP3-/- embryos. Thus, RAMP3 is apparently not essential for early vascular development, indicating that the functions of RAMP2 and RAMP3 differ substantially.

3.2. RAMP3 - - - mice show normal tumor angiogenesis and ischemiainduced angiogenesis

To assess angiogenesis in adult animals, we first examined tumor angiogenesis. S180 sarcoma cells were transplanted into bilateral axillary regions, after which tumor growth and angiogenesis were monitored.
A

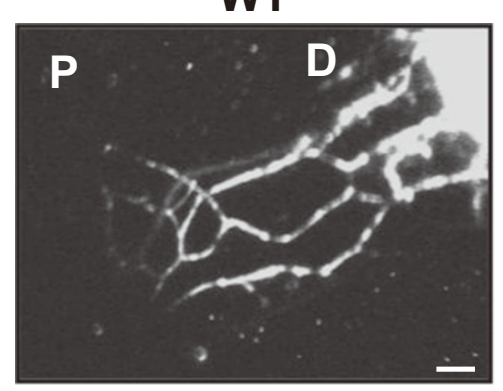

C

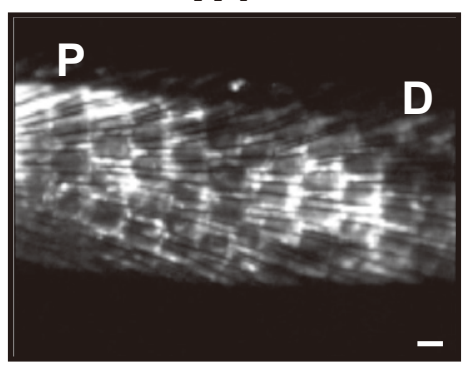

RAMP3-/-

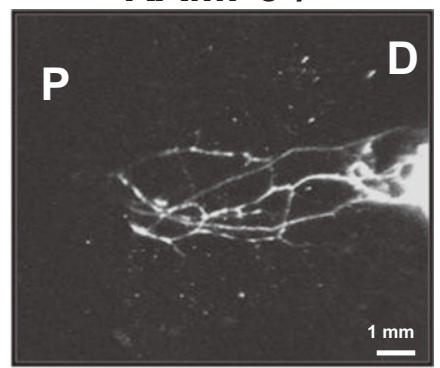

RAMP3-/-

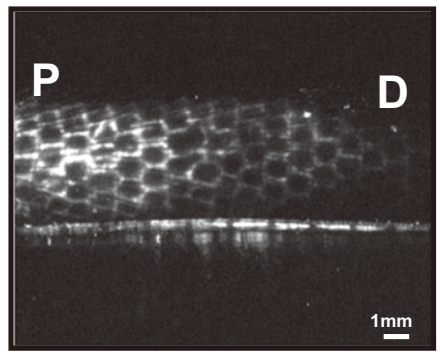

B

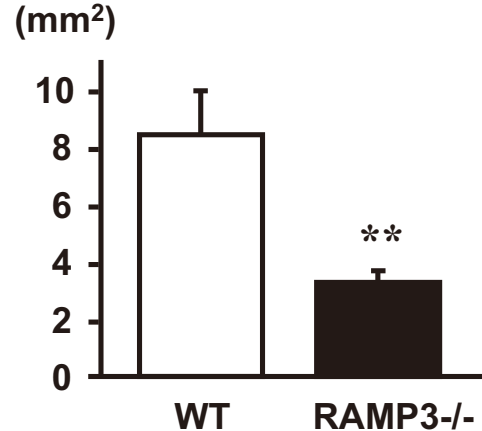

D

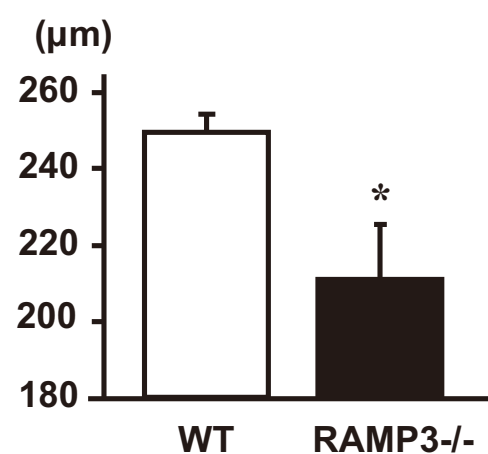

Fig. 4. Evaluation of the drainage function of subcutaneous lymphatic vessels in the ear and tail. (A) Fluorescence images of subcutaneous lymphatic vessels in the ear after indocyanine green (ICG) injection. ICG was injected into the edge of the ear and its lymphatic drainage was visualized after 15 min. P and D indicate the proximal (near head) and distal sides (near ear edge), respectively. Scale bars $=1 \mathrm{~mm}$. (B) Comparison of the area of visible ear lymphatics 15 min after ICG injection. $n=7$ in both WT and RAMP3 $-/-$. Bars are mean \pm SEM. $* * P<0.01$. (C) Fluorescence images of subcutaneous lymphatic vessels in the tail after ICG injection. The lymphatic drainage was visualized after 60 min. P, proximal side; $D$, distal side. Scale bars $=$ $1 \mathrm{~mm}$. (D) Comparison of diameter of visible tail lymphatics 60 min after ICG injection. $\mathrm{n}=6$ and 5 in WT and RAMP3-/ , respectively. Bars are mean \pm SEM. *P $<0.05$. RAMP3 $-/-$ mice showed delayed lymphatic drainage on lymphangiography. 
We observed that tumor blood flow, tumor growth, and capillary formation within tumors were all equivalent between wild-type (WT) and RAMP3 - / - mice (Figs. 2A-C). We then used the unilateral hind-limb ischemia model, in which the femoral arteries of mice were unilaterally resected, to examine collateral capillary formation. As shown in Figs. $3 \mathrm{~A}-\mathrm{D}$, blood flow recovery and capillary formation did not differ between WT and RAMP3 - / - mice. We also analyzed capillary formation in vitro by culturing aortic rings within collagen gel, and confirmed that there was no difference between angiogenesis in WT and RAMP3-/mice (data not shown). Again, these results are strikingly different from those obtained with AM $+/-$ and RAMP2 $+/-$ mice, both of which showed reduced neovascularization, as compared to their control mice $[17,23]$. In contrast, RAMP3 appears dispensable for angiogenesis in both embryos and adults.

Consistent with the results summarized above, gene expression analysis of ischemic limbs showed that the expression of the angiogenic factor VEGF-A did not differ between WT and RAMP3-/ - mice (Fig. 3E). On the other hand, the expression of a lymphatic vessel marker, podoplanin, tended to be lower in RAMP3-/- mice, which prompted us to examine in more detail lymphatic vessels in RAMP3 $-/-$ mice

\subsection{Lymphatic drainage is delayed in RAMP3 - - - mice}

To evaluate lymphatic vessel function, we first analyzed the drainage function of subcutaneous lymphatics. Fig. 4 shows the results obtained when we subcutaneously injected a fluorescent indicator, indocyanine green (ICG), into the ears (Figs. 4A, B) and tails (Figs. 4C, D) of mice, and assessed the extent of its drainage after $15 \mathrm{~min}$ and $60 \mathrm{~min}$, respectively. When we measured the area and diameter of fluorescencepositive vessels, we found that they were narrower in RAMP3-/mice than in WT mice. This indicates that drainage was delayed in RAMP3 - / - mice and suggests that the functionality of lymphatic vessels is altered in the absence of RAMP3.

\subsection{Intestinal lymphatic vessels appear abnormal in RAMP3 - - - mice}

Examination of intestinal lymphatic vessels within the mesentery revealed no apparent difference between untreated RAMP3 - / - mice and WT mice. However, when we used a feeding tube to feed the mice a high-fat meal after starvation for $16 \mathrm{~h}$, we observed that the intestinal lymphatic vessels in the mesentery of WT mice were dilated 6 $\mathrm{h}$ after the feeding, reflecting the conveyance of absorbed lipid from the intestine. In contrast, the intestinal lymphatics of RAMP3-/mice were comparatively narrow (Fig. 5A upper panels and 5B). This difference in intestinal lymphatic dilation between WT mice and RAMP3 $-/-$ mice disappeared by day 2 after the high-fat feeding (Fig. 5A lower panels and 5B).

Histological analysis showed shrinkage of the chyle vessels within the villi in RAMP3 - / - mice $6 \mathrm{~h}$ after the high-fat feeding (Fig. 5C). Together with the observation of delayed lymphatic drainage (Fig. 4), the shrinkage of chyle vessels and narrow intestinal lymphatics indicates delayed lymphatic absorption of lipid. Despite these observations, there was no significant difference between the body weights of
A

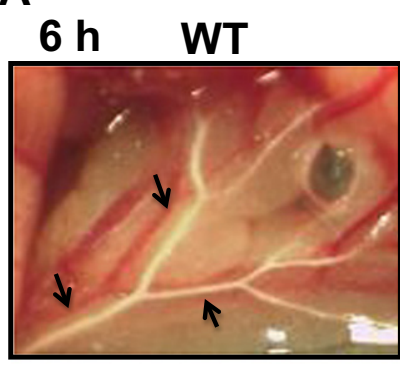

2 day WT

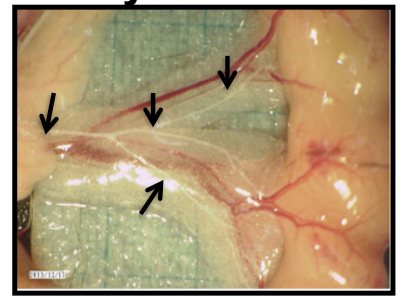

C

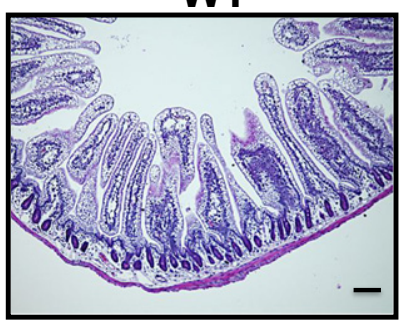

RAMP3-/-

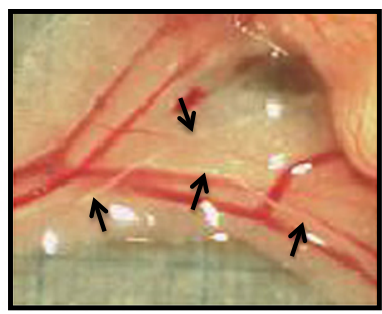

RAMP3-/-

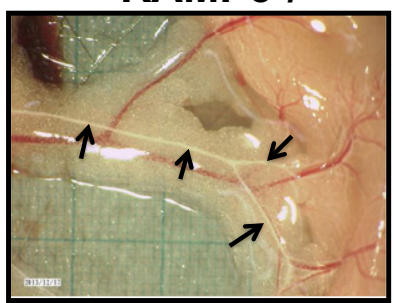

RAMP3-/-

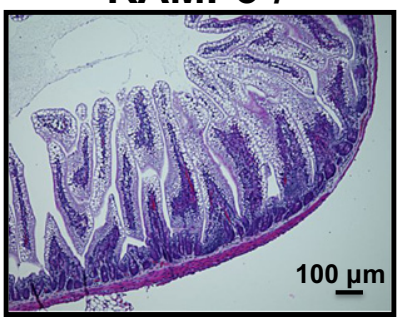

B
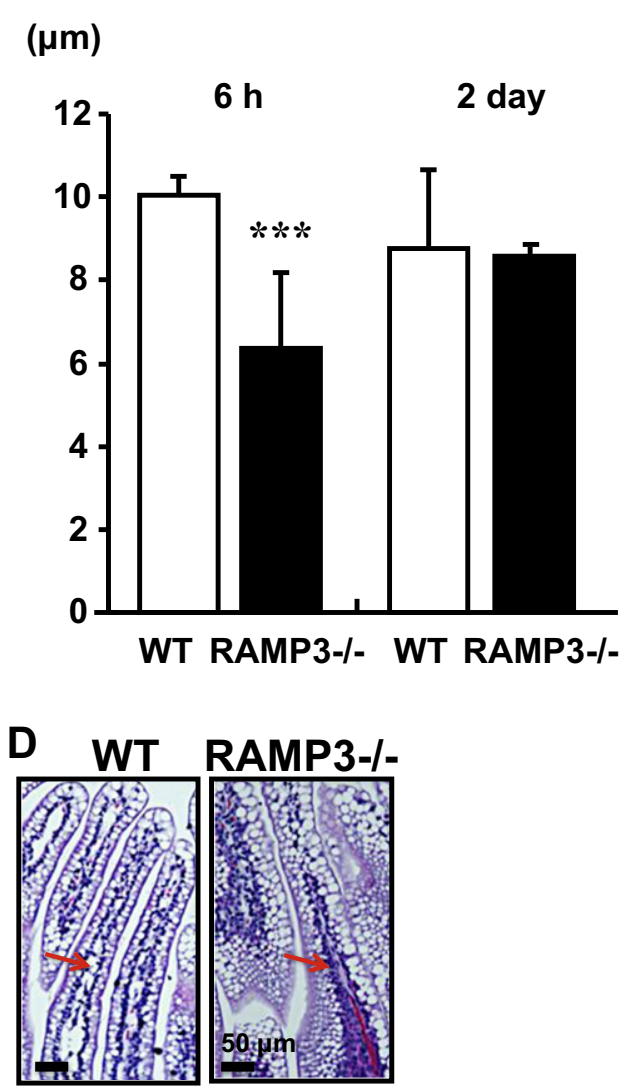

Fig. 5. Evaluation of intestinal lymphatic vessels. (A) Photos of intestinal lymphatic vessels (arrows) within the mesentery $6 \mathrm{~h}$ and 2 days after mice were fed a high-fat meal using a feeding tube. (B) Comparison of the diameters of intestinal lymphatic vessels. Bars are mean \pm SEM. $\mathrm{n}=8$ in each. ${ }^{* * *} \mathrm{P}<0.001$. Six hours after mice were fed a high-fat meal, the diameters of lymphatic vessels were significantly smaller in RAMP3-/ - mice than in WT mice, but the difference disappeared within 2 days. (C) Histological analysis (H\&E staining) of the intestine (15 cm distal to the pylorus) $6 \mathrm{~h}$ after the high-fat meal. (D) Magnification of (C). Arrows show the chyle vessels. RAMP3-/- mice showed shrinkage of the chyle vessels within villi. 
A. Yamauchi et al. / Journal of Molecular and Cellular Cardiology 77 (2014) $73-85$

79

A

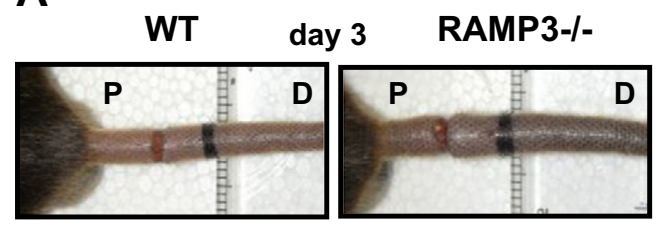

day 7

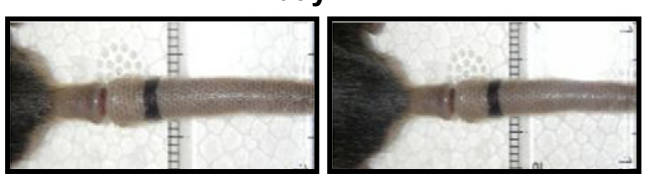

day 14

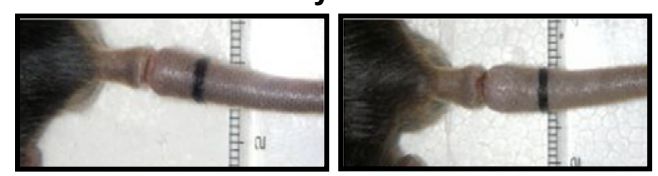

day 18

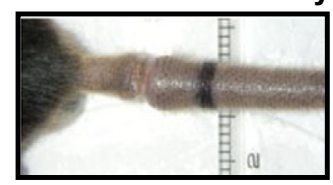

C

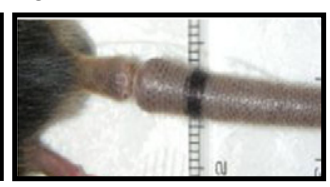

Ratio
B

Ratio

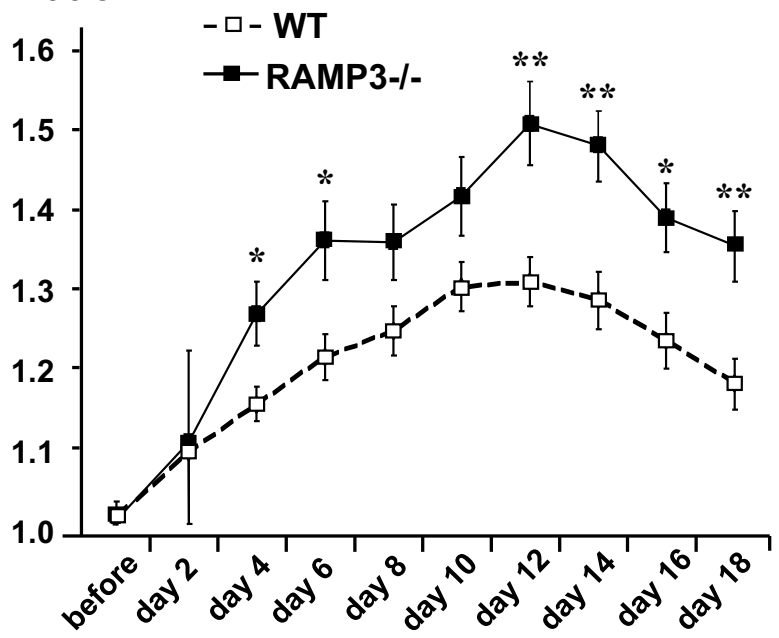

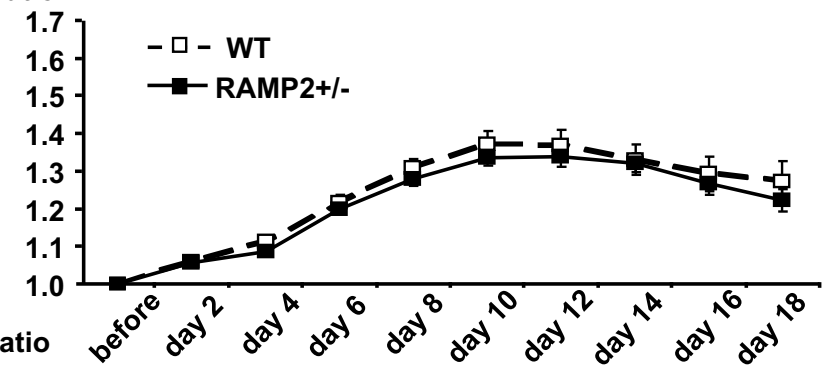
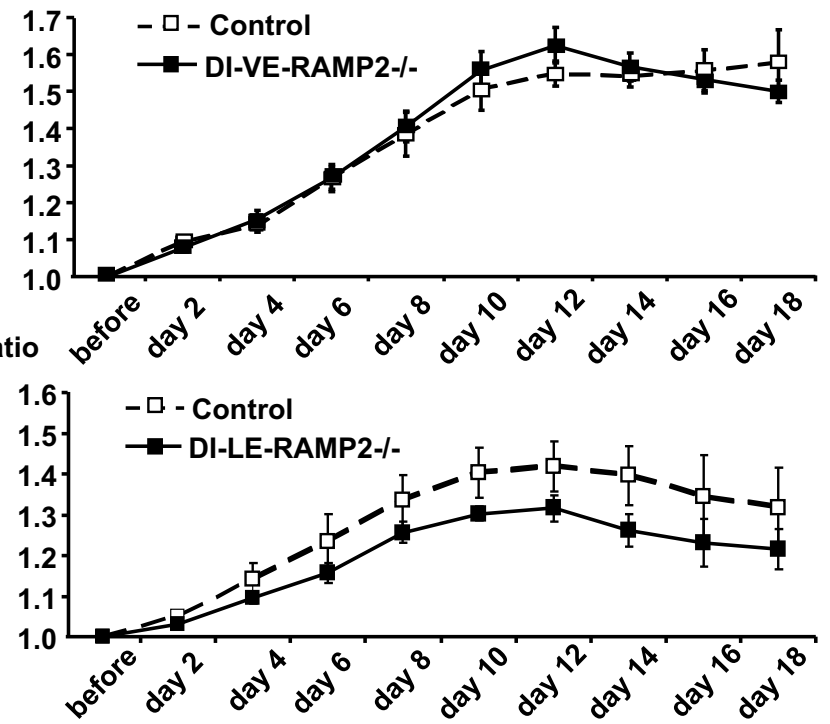

Fig. 6. Postoperative tail lymphedema model. (A) Appearance of the tails from WT and RAMP3-/ - mice in the postoperative lymphedema model. P, proximal side; D, distal side. (B) Quantification of the severity of tail edema. Ratios of tail diameters on the indicated postoperative day to the diameter before surgery are shown. Data are mean \pm SEM. $\mathrm{n}=22$ in each. ${ }^{* *} \mathrm{P}<0.01,{ }^{*} \mathrm{P}<0.05$. (C) Comparison of the severity of tail edema between RAMP2 knockout mice (RAM P2 $+/-$ ), drug-inducible vascular endothelial cell-specific RAMP2-/ (DI-VE-RAMP2-/-), drug-inducible lymphatic endothelial cell-specific RAMP2-/ - (DI-LE-RAMP2-/ - ), and their control mice. (RAMP2 +/-: $\mathrm{n}=20$ in each, DI-E-RAMP2-/-: $\mathrm{n}=9$ in each, DI-LE-RAMP2 - / - WT, $\mathrm{n}=8 ;-/-, \mathrm{n}=9$ ). RAMP $-/-$ mice showed more severe lymphedema than WT mice, whereas lymphedema in all of the RAMP2 knockout mice was comparable to their control. 
RAMP3 - / - mice and WT mice. Considering that the difference in lipid absorption disappears with free feeding, the disruption of lipid absorption in RAMP3 - / - mice appears to be subclinical under normal conditions.

\subsection{RAMP3 -/ - mice exhibit severe post-operative lymphedema}

To further investigate the role of the AM-RAMP3 system in the regulation of lymphatic function, we next used the tail lymphedema model. The mouse tail contains a highly regular network of lymphatic vessels in the skin. Therefore, circumferential removal of the skin from the tail obstructs lymphatic flow, resulting in acute lymphedema, enabling this system to serve as a model of secondary lymphedema [20]. Following the surgical procedure, the tails of all treated mice became edematous, with the edema reaching a peak on postoperative day 12 . Lymph flow was then gradually restored. Notably, from postoperative day 4 to day 18 , tail thickness was substantially greater in RAMP3 - / - mice than in WT mice (Figs. 6A, B).

We also used the tail lymphedema model in RAMP2 +/-, DI-VERAMP2 - / - and DI-LE-RAMP2 - / - mice. In contrast to RAMP3 - / mice, the lymphedema did not differ from the control in any of these
A

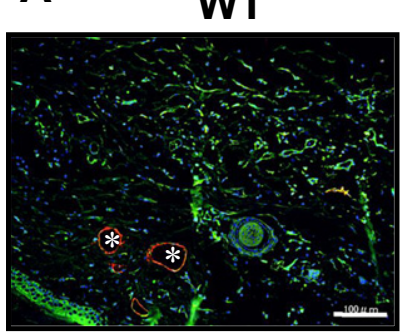

C

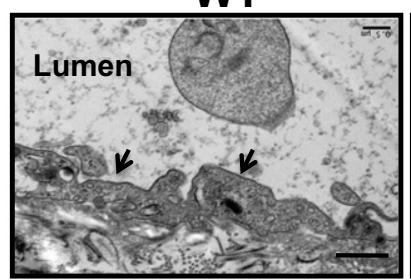

RAMP3-/-

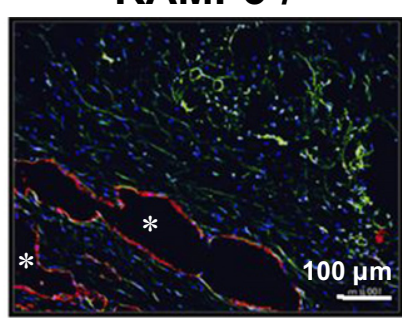

RAMP3-/-

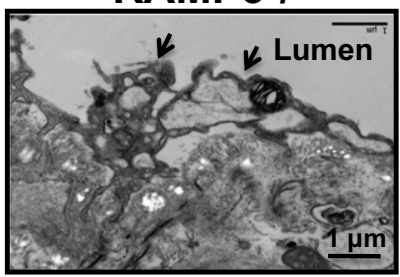

B

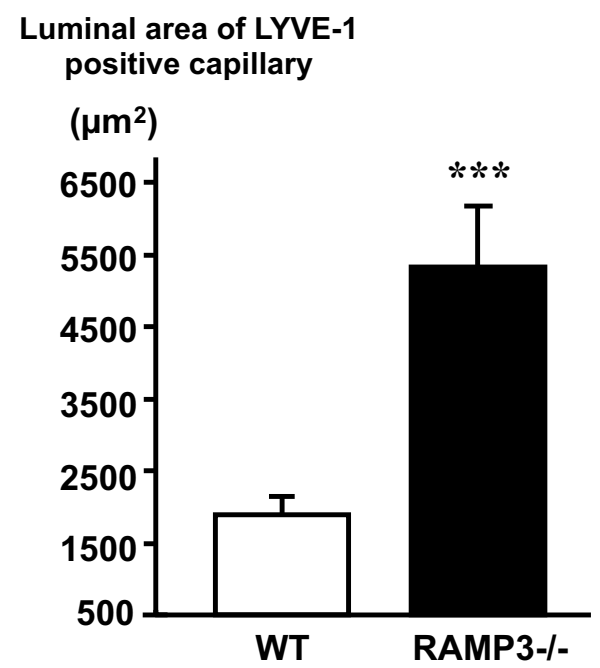

D
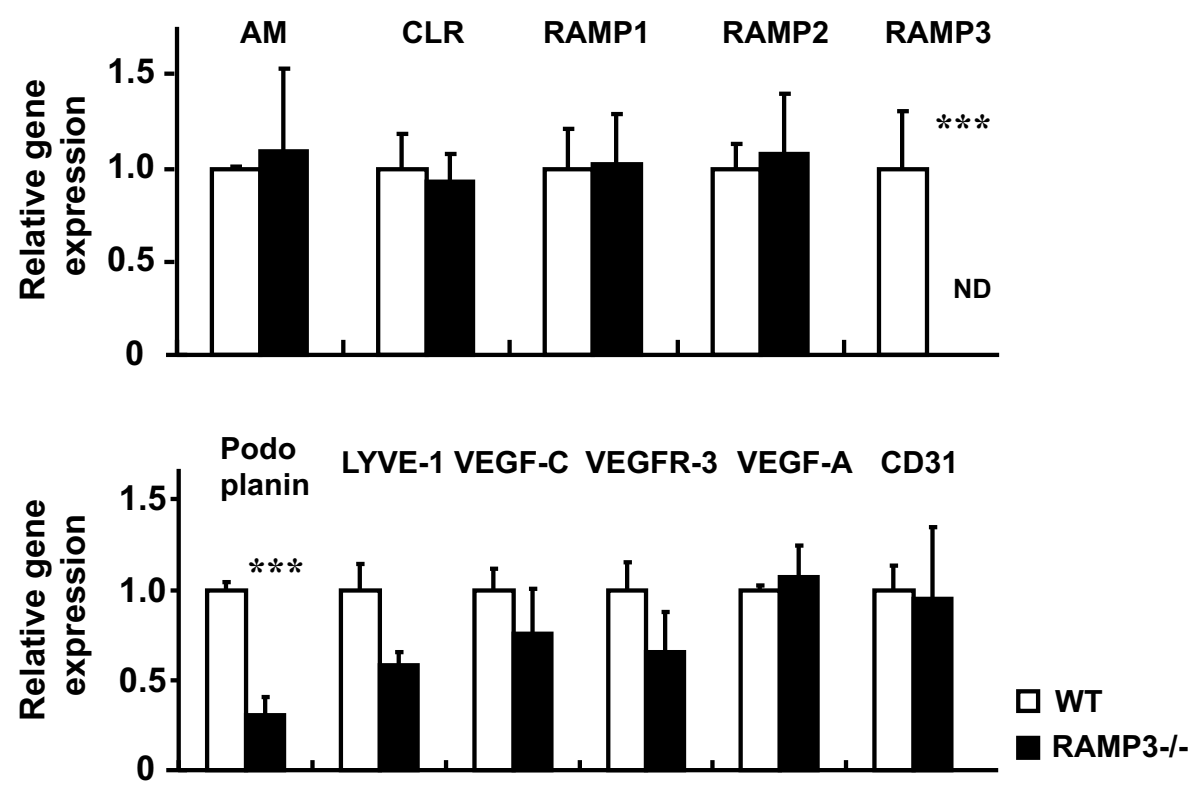

Fig. 7. Structural changes in lymphatic capillaries in the tail lymphedema model. (A) Fluorescent immunostaining of sections of mouse tail in the lymphedema model: green, CD31 (endothelial cell marker); red, LYVE-1 (lymphatic endothelial cell marker); blue, DAPI. RAMP3 - - - tails showed abnormal dilation of the lymphatic capillaries (compare regions indicated by asterisks). Scale bars $=100 \mu \mathrm{m}$. (B) Comparison of luminal areas of LYVE-1-positive lymphatic capillaries. Data are shown as the lymphatic luminal area per microscopic field (200x). $\mathrm{n}=8$ in both WT and RAMP3 $-/-$. The mean of 3 fields in each mouse was used for statistical analysis. ${ }^{* * *} \mathrm{P}<0.001$. (C) Electron micrographs showing lymphatic endothelial cells (arrows). Lymphatic endothelial cells from RAMP3 - / - mice appear structurally abnormal, with enlarged intracellular vacuoles. Scale bars = $1 \mu \mathrm{m}$. (D) Quantitative real-time PCR analysis of samples from the tail lymphedema model collected on day 10. Shown are the relative gene expression levels for AM, CLR and RAMPs (upper panel), as well as marker genes of lymphatic and blood vessels (lower panel). Data from the WT group were assigned a value of 1 . Bars are mean \pm SEM. ${ }^{* * *} \mathrm{P}<0.001$. $\mathrm{n}=8$ in each. ND, not detected. RAMP3 - / - tissue showed significantly weaker expression of the lymphatic vessel marker podoplanin, whereas blood vessel markers were unchanged. 

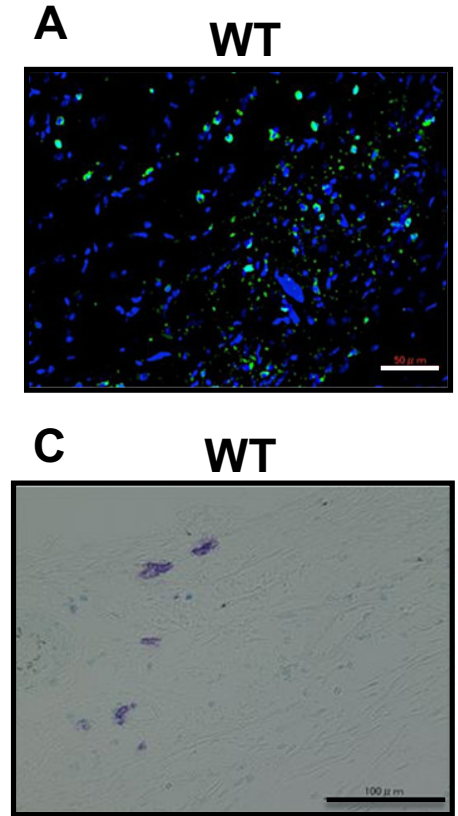

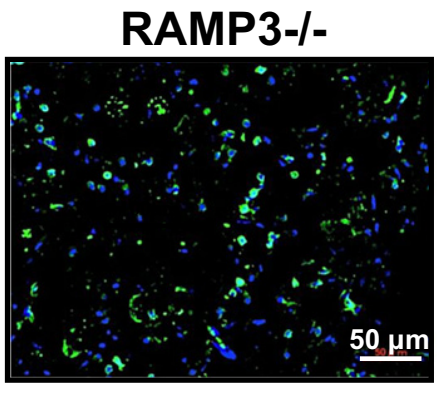

RAMP3-/-

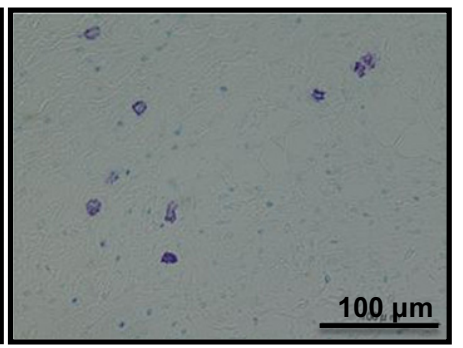

B

(ratio)

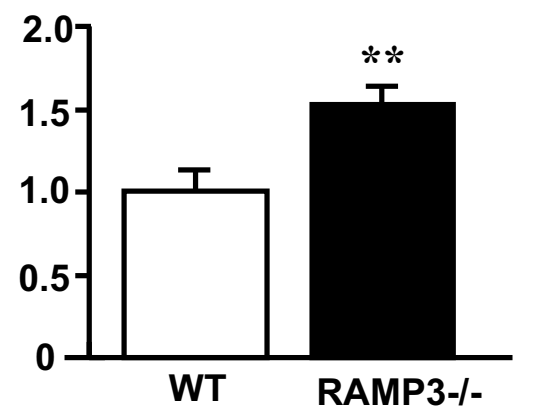

(ratio)

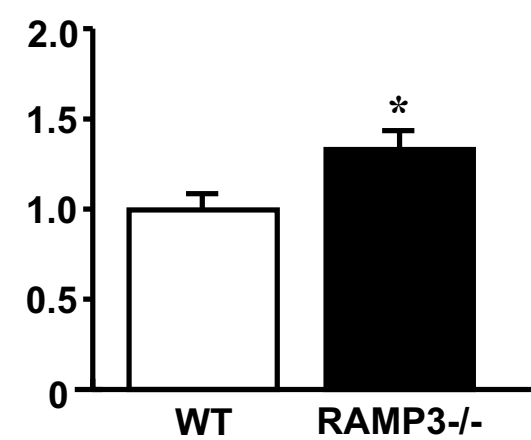

Fig. 8. Invasion of leukocytes in the tail lymphedema model. (A) Fluorescence immunostaining of sections of tail from the lymphedema model on postoperative day 10 : green, CD45 (leukocyte cell marker); blue, DAPI. Scale bars $=50 \mu \mathrm{m}$. (B) Comparison of CD45-positive leukocytes between WT and RAMP3-/ - mice. Data are shown as the ratio when WT was assigned a value of 1 . Bars are mean \pm SEM. ${ }^{* *} \mathrm{P}<0.01 . \mathrm{n}=8$ in each. (C) Toluidine blue staining showing mast cell invasion in the tail lymphedema model. Scale bars $=100 \mu \mathrm{m}$. (D) Comparison of mast cell numbers between WT and RAMP3-/ - mice. ${ }^{*} \mathrm{P}<0.05 . \mathrm{n}=12$ in each. RAMP3 $-/-$ mice showed enhanced leukocyte invasion, including mast cells.

RAMP2 knockout mice (Fig. 6C). Given that RAMP2 and RAMP3 are equally expressed in both blood vessels and lymphatics, and that they contribute equally to the formation of high-affinity AM receptors with CLR, it is noteworthy that RAMP2 knockout did not aggravate the tail edema. RAMP2 thus does not appear to be meaningfully involved in the regulation of lymphatics.

\subsection{Lymphatic capillaries appear abnormal in RAMP3 - - - mice}

Using the tail lymphedema model, we next visualized the lymphatic vessels in the injury site by staining with an anti-LYVE- 1 antibody, while blood vessels were visualized by staining with an anti-CD31 antibody (Fig. 7A). On postoperative day 12, when the lymphedema was most severe, the density of lymphatics and blood vessels did not differ between WT mice and RAMP3 - / - mice (data not shown). On the other hand, we observed abnormal dilatation of LYVE-1-positive lymphatic vessels in RAMP3-/ - mice (Fig. 7A, compare the regions marked with an asterisk). The luminal areas of lymphatic vessels were about 3 times larger in RAMP3 - / - mice than in WT mice (Fig. 7B). Furthermore, electron microscopic observation revealed that lymphatic endothelial cells in RAMP3 - / - mice were structurally abnormal, with enlarged intracellular vacuoles (Fig. 7C, compare regions indicated by arrows). Gene expression analysis of edematous tail samples showed no difference in the expression of two blood vessel markers, CD31 and VEGF-A, between RAMP3-/ - mice and WT mice; however, the expression of lymphatic vessel markers, especially podoplanin, was diminished in RAMP3-/ mice (Fig. 7D). These findings demonstrate directly that the AMRAMP3 system is necessary for proper lymphatic capillary function after injury, and that the dilatation of lymphatic vessels in RAMP3 - / - mice most likely reflects disruption of lymphatic drainage.
3.7. Inflammatory cells accumulate in the edematous tails of RAMP3 - - mice

Given that lymphedema is exacerbated by disruption of lymphatic drainage in RAMP3-/ - mice, we speculated that the mice would also experience prolonged inflammatory reactions after the tail injury. Consistent with that idea, we found that there was greater accumulation of CD45-positive leukocytes in RAMP3-/ - mice than in WT mice (Figs. $8 \mathrm{~A}, \mathrm{~B})$. In addition, the number of toluidine blue-positive mast cells was also increased in RAMP3-/ - mice (Figs. 8C, D).

3.8. RAMP3 -/ - lymphatic endothelial cells exhibit reduced proliferation, migration, and Akt activation in vitro

Finally, we used in vitro assays to directly evaluate lymphatic endothelial cells isolated from WT and RAMP3 - / - embryos. We first used RT-PCR to confirm the expression of AM, CLR and RAMPs in lymphatic endothelial cells (Fig. 9A). Among the RAMPs, we found that RAMP3 was most highly expressed in WT lymphatic endothelial cells. We then used scratch-wound assays, performed in the presence and absence of growth factors supplied with the EGM-2-MV medium, to evaluate the recovery of the endothelial monolayer within the scratched area. We found that re-endothelialization was significantly delayed with RAMP3 $-/$ - cells (Figs. 9B, C). The addition of $10^{-7} \mathrm{M}$ AM to the medium enhanced re-endothelialization by WT cells, but it had no effect on RAMP3-/ - cells (Figs. 9D, E). We also analyzed the cellular proliferation of the isolated lymphatic endothelial cells by BrdU assay, however, we could not find a difference (data not shown). We speculated that the delayed re-endothelialization of RAMP3 - / - was migrationdependent. Using Western blot analysis, we found that AM 


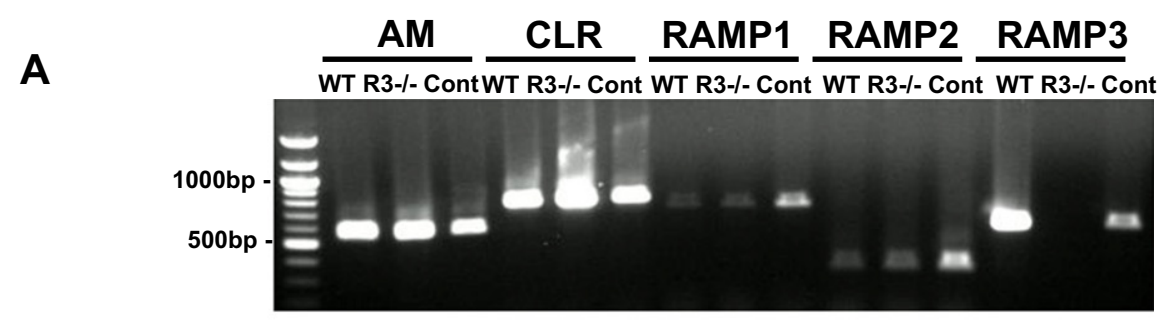

B
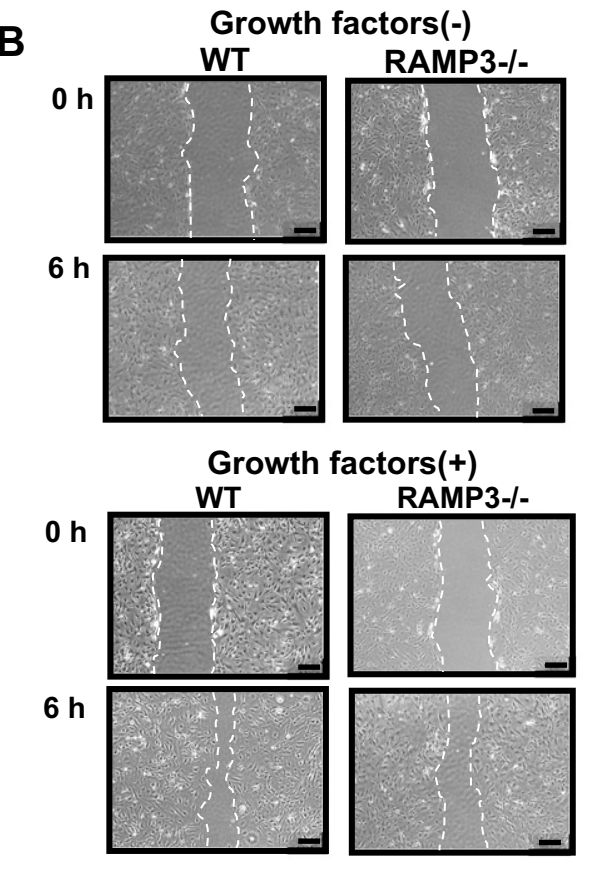

C

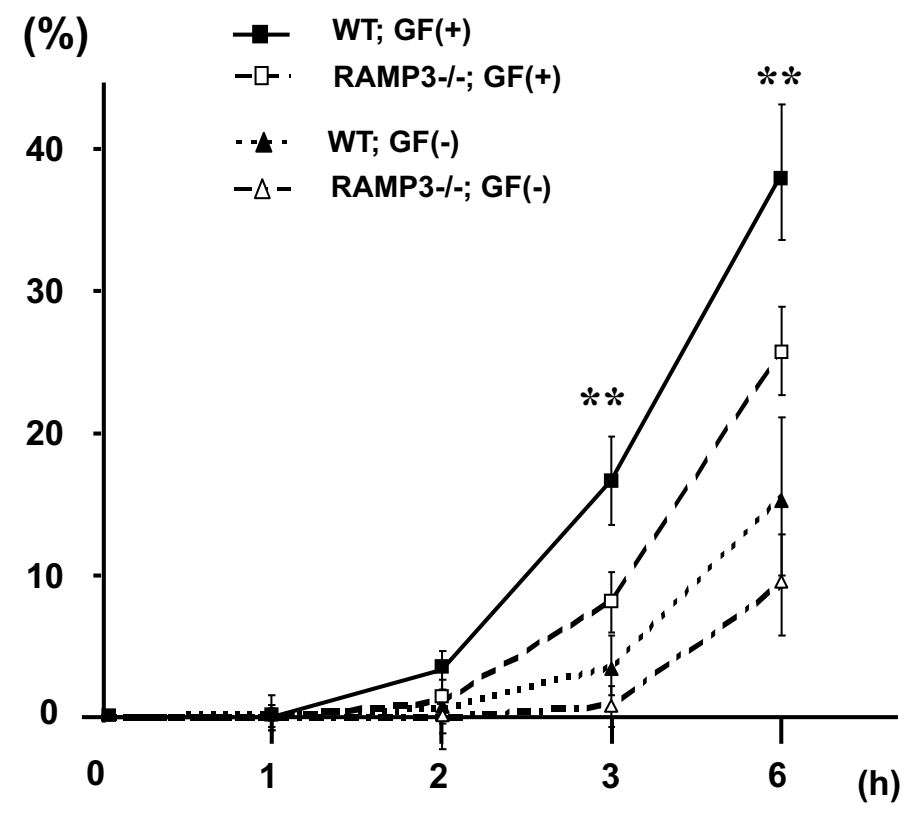

D
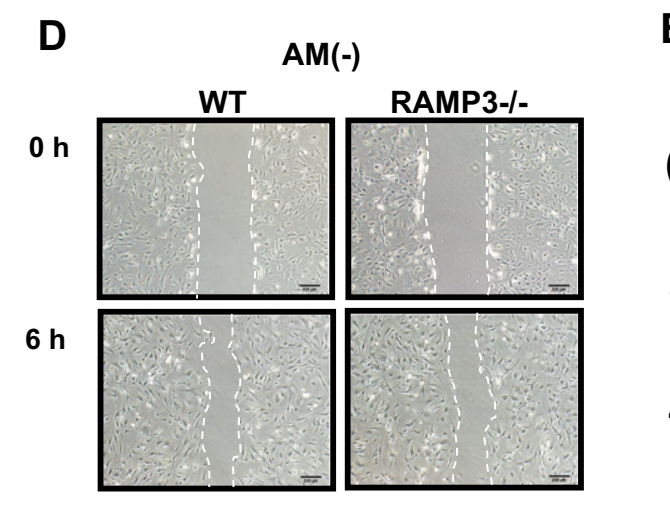

E

$(\%)$
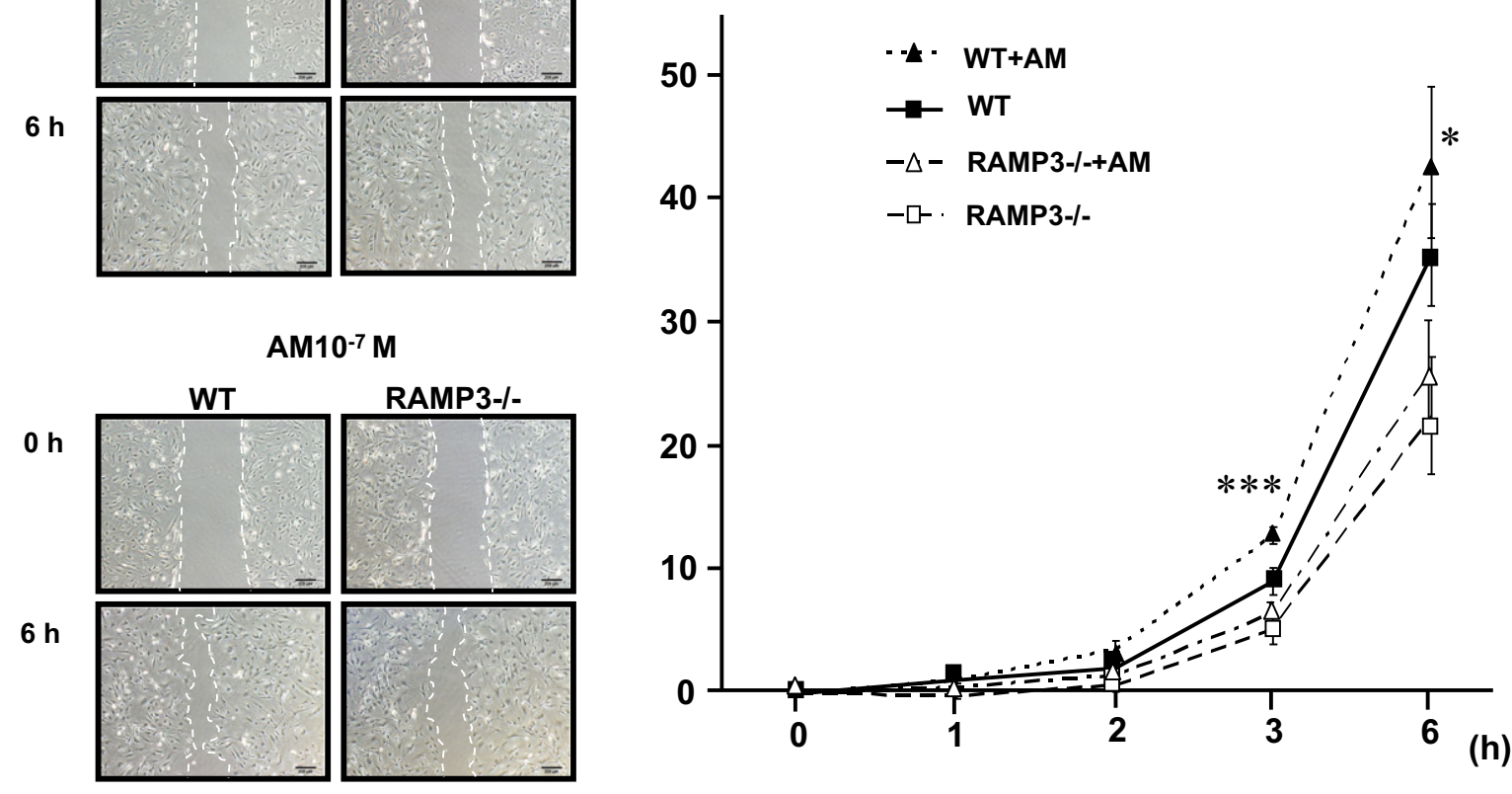
$\mathbf{F}$

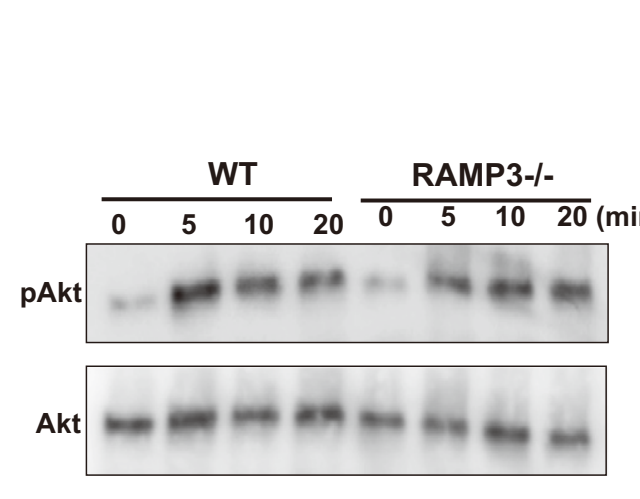

G

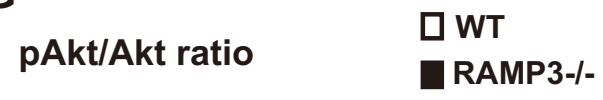

Fig. 9. In vitro scratch-wound assay using primary cultured lymphatic endothelial cells. (A) RT-PCR analysis of AM, CLR and RAMPs in lymphatic endothelial cells isolated from WT, RAMP3-/(R3-/-), and control (cDNA from mouse embryonic fibroblasts) samples. (B) Representative photomicrographs of in vitro scratch-wound assays with lymphatic endothelial cells from WT and RAMP3-/ - mice. Images were acquired $0 \mathrm{~h}$ and $6 \mathrm{~h}$ after scratching confluent cultures in EGM-2-MV medium with (lower panels) and without (upper panels) growth factors supplied with the medium by the manufacturer. Scale bars $=200 \mu \mathrm{m}$. (C) Percentage cell-covered area in the scratch-wound assay with WT and RAMP3 $-/-$ lymphatic endothelial cells, with or without growth factors (GF). Data are shown as mean \pm SEM. $n=9$ (in each dish, the mean from the 4 images was used). ${ }^{* *} \mathrm{P}<0.01$ (WT $+\mathrm{GF}$ vs. RAMP3 $-/-+\mathrm{GF}$ ). Lymphatic endothelial cells from RAMP3 $-/-$ mice showed delayed migration. (D) Scratch-wound assays with lymphatic endothelial cells, with or without AM $\left(10^{-7} \mathrm{M}\right)$. Scale bars $=200 \mu \mathrm{m}$. (E) Percentage cell-covered area, with and without AM (no growth factors). $\mathrm{n}=9$ (in each dish, the mean from the 4 images was used). ${ }^{* * *} \mathrm{P}<0.001,{ }^{*} \mathrm{P}<0.05$ (WT + AM vs. RAMP3 $-/-+$ AM). AM administration enhanced the proliferation and migration of WT lymphatic endothelial cells, but had no effect on RAMP3 - / - cells. (F) Western blot analysis of Akt and p-Akt levels in lymphatic endothelial cells stimulated with AM $\left(10^{-7} \mathrm{M}\right)$. Optical densities were quantified, and relative Akt phosphorylation levels are shown in the bar graph. p-Akt/Akt in WT cells at 0 min was set to 1. Bars are mean \pm SEM. * $\mathrm{P}<0.05$ (Mann-Whitney U test). The experiment was repeated six times. The level of Akt activation was lower in RAMP3-/ - cells than in WT cells.

administration to cultured lymphatic cells upregulated activation of the cell survival signal, Akt, although the levels were significantly lower in RAMP3-/ - cells than in WT cells (Figs. 9F, G).

\section{Discussion}

In this study, we used genetically engineered mice to evaluate the functions of endogenous RAMP2 and RAMP3, two accessory proteins that, along with CLR, comprise AM receptors. We previously showed that RAMP2 is essential for angiogenesis and vascular homeostasis in both embryos and adults $[17,18]$. In the present study, we found that the phenotypes of RAMP2-/ - and RAMP3 - / - mice are strikingly different: whereas RAMP2 $-/-$ mice die in utero due to vascular abnormalities, RAMP3 - - - mice are born normally with no blood vessel or lymphatic abnormalities. In addition, post-natal angiogenesis was also normal in RAMP3 - / - mice, whereas RAMP2 +/ - mice showed reduced neovascularization. These observations clearly indicate that, unlike RAMP2, RAMP3 is not essential for the angiogenic function of AM.

Apart from its angiogenic function, AM also reportedly possesses lymphangiogenic activity. Nikitenko et al. found that secondary lymphedema induced in the hind-limb skin incision model was more severe in $\mathrm{AM}+/-$ mice, and the edema was prevented when circulating AM levels were restored by systemic delivery of exogenous peptide [24]. In addition, Hoopes et al. observed that drug-induced knockout of CLR or AM leads to chronic edema and dermal lymphatic insufficiency in adult mice [25]. These earlier reports suggest that AM-CLR signaling is important for the maintenance of normal lymphatic vessels; however, in both AM and CLR knockout mice, all of the signaling mediated by RAMPs (RAMP1-3) are functionally deleted, as either the ligand or receptor is absent. Therefore, to determine which RAMP is fundamentally important for the regulation of lymphatic vessels by AM, it was necessary to separately delete each RAMP isoform.

To evaluate the lymphatic vessels in RAMP3 - / - mice, we first performed fluorescence lymphography using indocyanine green (ICG), which is used clinically to assess lymphatic function [26]. ICG is rapidly taken up by initial lymphatics and, upon surface illumination with tissue-penetrating near infrared excitation light, the fluorescence emitted by the ICG-laden lymph can be detected with high spatial and temporal resolution, enabling visualization of lymphatic drainage [27]. We found that ICG drainage by subcutaneous lymphatic vessels was delayed in RAMP3 - / - mice. Similarly, after feeding RAMP3 - / - mice a high-fat meal, chyle transport by intestinal mesenteric lymphatics also showed a delay. In the gastrointestinal tract, the lymphatic system mediates the absorption of lipid from the intestine and transports the lipids, in the form of chyle, to the liver $[27,28]$. The mechanism of lipid absorption through intestinal lymphatic vessels is not fully understood, but it would be expected that lipid transport would be delayed if transcellular and paracellular transport by lymphatic endothelial cells were compromised [29].

Despite the apparently altered lymphatic function, RAMP3-/mice exhibited no lymphatic abnormalities during development, and there were no spontaneous occurrences of edema in adults. Moreover, narrowing of the intestinal lymphatic vessels was not apparent in free-feeding mice. Thus, the changes observed in RAMP3 - / - mice appear subclinical, only becoming manifest when a substantial load is applied. In a tail lymphedema model, for example, the induced edema was significantly worse in RAMP3 - / - mice than in WT mice. Histological analysis revealed abnormal dilatation of lymphatic vessels similar to that seen clinically when there is a malfunction of lymphatic drainage, such as after lymph node resection [30,31]. On the other hand, the numbers of CD31-positive blood vessels and LYVE-1-positive lymphatic vessels were unaffected by RAMP3 deletion, indicating that progression of angiogenesis and lymphangiogenesis was not altered. Instead electron microscopic observations and gene expression analysis suggest that abnormalities in lymphatic endothelial cells are the main cause for the delayed lymphatic drainage in RAMP3-/ - mice.

In the tail lymphedema model, we found that leukocyte numbers in the injured region were greater in RAMP3-/ - mice than in WT mice, which is consistent with the reported relationship between lymphangiogenesis and inflammation. Huggenberger et al. found that delivery of the lymphangiogenic factor VEGF-C to the skin blocked the development of chronic skin inflammation in a mouse ear edema model, whereas the systemic inhibition of VEGFR-3, the main VEGF-C receptor, increased inflammatory cell accumulation together with the reduction of lymphangiogenesis [32]. In our model, tail thickness continued to be greater in RAMP3 - / - until long after the peak of edema. 
We speculate that the resolution of inflammation is delayed or disrupted in RAMP3-/ - mice. After an injury, leukocytes infiltrate the injured site, and at a late stage in the inflammation process, they undergo apoptosis and clearance by phagocytes, leading to the resolution of the inflammation [33]. Lymphatic vessels newly generated after the injury contribute to the clearance of the apoptotic cells as well as the interstitial fluid. For that reason, dysfunction of lymphatic drainage would likely prolong the inflammation in RAMP3 - / - mice. In addition, mast cells were recently shown to contribute to innate immunity and tissue repair, though they can be detrimental when chronically stimulated [31]. Consequently, the increased numbers of mast cells seen in RAMP3 - / - mice may also have contributed to the prolonged inflammation and edema.

Using scratch-wound assays, we found that RAMP3-/ - lymphatic endothelial cells have a lower migration capacity than WT cells. This observation supports our in vivo data that malfunction of lymphatic drainage in RAMP3-/ - reflects a change in lymphatic endothelial cell function. Moreover, whereas AM promoted migration of WT lymphatic endothelial cells, it had no effect on migration of RAMP3 - / - cells, which confirms that altered lymphatic function is dependent on the deletion of the AM-RAMP3 signaling system. Lymphatic cell migration is thought to primarily determine the lymph flow in the skin injury model [34]. Taken together, the altered lymphatic function in RAMP3 - / - actually depends on the deletion of the AM-RAMP3signaling system in lymphatic endothelial cells.

RAMPs reportedly also bind to class B GPCRs other than CLR, including receptors for calcitonin, glucagon and vasoactive intestinal peptide, and it has been suggested that RAMPs may function as chaperons to modulate internalization and recycling of those receptors [33]. It therefore remains a possibility that our observations in RAMP3 $-/$ - mice reflect changes in receptor systems, apart from AM and CLR. To further confirm that the phenotypes of RAMP3-/ - lymphatic endothelial cells are dependent on the deletion of the AM-RAMP3-CLR signaling system, we analyzed the change of intracellular signaling when stimulated by AM. In various cells, AM reportedly exerts anti-apoptotic effects mediated via the PI3K-Akt pathway [23,35]. In this study, RAMP3 - / showed a lower response to AM in Akt-activation, which actually represents downregulation of AM-RAMP3-CLR signaling in the lymphatic endothelial cells of RAMP3-/-.

Lymphedema in humans is a chronic condition caused by disruption of lymphatic drainage, often after lymph node resection and radiation therapy. In extreme cases, supermicrosurgical lymphaticovenular anastomosis may be indicated [36,37], but the operation is not curative, and continued therapy remains necessary. On the other hand, in some cancers, invasion of the lymphatic system enables transport of tumor cells to distant lymph nodes and organs. We anticipate that a better understanding of the molecular and cellular mechanisms involved in the regulation of lymphatic vessels will bring new insight into the treatment of these diseases. Lymphatic research has lagged behind vascular research, but it has been accelerated by the discovery of several lymphaticspecific markers, including VEGFR-3, LYVE-1 and Prox1 [38]. In the present study, we showed that the AM-RAMP3 system is a novel regulator controlling lymphatic function in adults. A clinical trial of AM has already been run for inflammatory bowel diseases, as AM exerts antiinflammatory and anti-bacterial effects and stimulates mucosal regeneration. But AM has a very short half-life in the blood, which makes its use in the treatment of chronic diseases difficult. It is therefore noteworthy that we are able to modulate AM function in lymphatics by modulating RAMP3. The AM-RAMP3 system could be a novel therapeutic target for controlling post-operative lymphedema.

\section{Conclusion}

In summary, using RAMP2 and RAMP3 genetically engineered mice, we clarified their functional differentiation in the vascular system. The AM-RAMP2 system mainly regulates vascular development and postnatal angiogenesis, and the AM-RAMP3 system mainly regulates lymphatic function in adults. Various effects of AM might be determined by such regulatory differentiations. Our findings also provide a basis for the development of drugs that could potentially modulate RAMP2 and RAMP3 and, thereby, the angiogenic and lymphatic effects of AM, respectively.

\section{Sources of funding}

This study was supported by the Funding Program for Next Generation World-Leading Researchers (NEXT Program) from the Cabinet Office, Government of Japan (No. LS053), a Grant-in-Aid for Scientific Research (KAKENHI) (No.26293183, 26293085, 25460330, 26460337), a research grant for Cardiovascular Diseases from the National Cardiovascular Center, and research grants from the Novartis Foundation for Gerontological Research, the Ichiro Kanehara Foundation, the Cosmetology Research Foundation, the SENSHIN Medical Research Foundation, the Nagao Memorial Fund, the Kanzawa Medical Research Foundation, the Ono Medical Research Foundation, the Nakatomi Foundation, the Japan Heart Foundation \& Astellas/Pfizer Grant for Research on Atherosclerosis Update, the Research Foundation for Opto-Science and Technology, the Japan Vascular Disease Research Foundation, and the Takeda Science Foundation.

\section{Disclosure statement}

\section{None.}

\section{Acknowledgment}

AM was kindly provided by Dr. Kangawa, Director General of the National Cardiovascular Center Research Institute, Japan. VE-cadherinCreERT2 mice were kindly provided by Dr. Ralf H. Adams of the Department of Tissue Morphogenesis, University of Munster. Proxl-CreERT2 mice were kindly provided by Dr. Guillermo Oliver of St. Jude Children's Research Hospital and GIE-CERBM (IGBMC).

\section{References}

[1] Kitamura K, Kangawa K, Kawamoto M, Ichiki Y, Nakamura S, Matsuo H, et al. Adrenomedullin: a novel hypotensive peptide isolated from human pheochromocytoma. Biochem Biophys Res Commun 1993;192:553-60.

[2] Jougasaki M, Wei CM, Aarhus LL, Heublein DM, Sandberg SM, Burnett Jr JC. Renal localization and actions of adrenomedullin: a natriuretic peptide. Am J Physiol 1995; 268:F657-63.

[3] Nishikimi T, Matsuoka H. Cardiac adrenomedullin: its role in cardiac hypertrophy and heart failure. Curr Med Chem Cardiovasc Hematol Agents 2005;3:231-42.

[4] Samson WK, Murphy T, Schell DA. A novel vasoactive peptide, adrenomedullin, inhibits pituitary adrenocorticotropin release. Endocrinology 1995;136:2349-52.

[5] Petrie MC, Hillier C, Morton JJ, McMurray JJ. Adrenomedullin selectively inhibits angiotensin II-induced aldosterone secretion in humans. J Hypertens 2000;18:61-4.

[6] Isumi Y, Kubo A, Katafuchi T, Kangawa K, Minamino N. Adrenomedullin suppresses interleukin-1beta-induced tumor necrosis factor-alpha production in Swiss 3T3 cells. FEBS Lett 1999;463:110-4.

[7] Shimosawa T, Shibagaki Y, Ishibashi K, Kitamura K, Kangawa K, Kato S, et al. Adrenomedullin, an endogenous peptide, counteracts cardiovascular damage. Circulation 2002;105:106-11.

[8] Shimosawa T, Ogihara T, Matsui H, Asano T, Ando K, Fujita T. Deficiency of adrenomedullin induces insulin resistance by increasing oxidative stress. Hypertension 2003:41:1080-5.

[9] Kano H, Kohno M, Yasunari K, Yokokawa K, Horio T, Ikeda M, et al. Adrenomedullin as a novel antiproliferative factor of vascular smooth muscle cells. J Hypertens 1996; 14:209-13.

[10] Miyashita K, Itoh H, Sawada N, Fukunaga Y, Sone M, Yamahara K, et al. Adrenomedullin promotes proliferation and migration of cultured endothelial cells. Hypertens Res 2003(26 Suppl.):S93-8

[11] Iwasaki H, Eguchi S, Shichiri M, Marumo F, Hirata Y. Adrenomedullin as a novel growth-promoting factor for cultured vascular smooth muscle cells: role of tyrosine kinase-mediated mitogen-activated protein kinase activation. Endocrinology 1998; 139:3432-41.

[12] McLatchie LM, Fraser NJ, Main MJ, Wise A, Brown J, Thompson N, et al. RAMPs regulate the transport and ligand specificity of the calcitonin-receptor-like receptor. Nature 1998;393:333-9. 
[13] Kuwasako K, Cao YN, Nagoshi Y, Kitamura K, Eto T. Adrenomedullin receptors: pharmacological features and possible pathophysiological roles. Peptides 2004;25:2003-12.

[14] Morfis M, Christopoulos A, Sexton PM. RAMPs: 5 years on, where to now? Trends Pharmacol Sci 2003;24:596-601.

[15] Parameswaran N, Spielman WS. RAMPs: the past, present and future. Trends Biochem Sci 2006;31:631-8.

[16] Shindo T, Kurihara Y, Nishimatsu H, Moriyama N, Kakoki M, Wang Y, et al. Vascular abnormalities and elevated blood pressure in mice lacking adrenomedullin gene. Circulation 2001;104:1964-71.

[17] Ichikawa-Shindo Y, Sakurai T, Kamiyoshi A, Kawate H, Iinuma N, Yoshizawa T, et al. The GPCR modulator protein RAMP2 is essential for angiogenesis and vascular integrity. J Clin Invest 2008;118:29-39.

[18] Koyama T, Ochoa-Callejero L, Sakurai T, Kamiyoshi A, Ichikawa-Shindo Y, Iinuma N, et al. Vascular endothelial adrenomedullin-RAMP2 system is essential for vascular integrity and organ homeostasis. Circulation 2013;127:842-53.

[19] Couffinhal T, Silver M, Zheng LP, Kearney M, Witzenbichler B, Isner JM. Mouse model of angiogenesis. Am J Pathol 1998;152:1667-79.

[20] Jin D, Harada K, Ohnishi S, Yamahara K, Kangawa K, Nagaya N. Adrenomedullin induces lymphangiogenesis and ameliorates secondary lymphoedema. Cardiovasc Res 2008;80:339-45.

[21] Kazenwadel J, Secker GA, Betterman KL, Harvey NL. In vitro assays using primary embryonic mouse lymphatic endothelial cells uncover key roles for FGFR1 signalling in lymphangiogenesis. PLoS One 2012;7:e40497.

[22] Liang CC, Park AY, Guan JL. In vitro scratch assay: a convenient and inexpensive method for analysis of cell migration in vitro. Nat Protoc 2007;2:329-33.

[23] limuro S, Shindo T, Moriyama N, Amaki T, Niu P, Takeda N, et al. Angiogenic effects of adrenomedullin in ischemia and tumor growth. Circ Res 2004;95:415-23.

[24] Nikitenko LL, Shimosawa T, Henderson S, Makinen T, Shimosawa H, Qureshi U, et al. Adrenomedullin haploinsufficiency predisposes to secondary lymphedema. J Invest Dermatol 2013;133:1768-76.

[25] Hoopes SL, Willcockson HH, Caron KM. Characteristics of multi-organ lymphangiectasia resulting from temporal deletion of calcitonin receptor-like receptor in adult mice. PLoS One 2012;7:e45261.

[26] Yamamoto T, Narushima M, Doi K, Oshima A, Ogata F, Mihara M, et al. Characteristic indocyanine green lymphography findings in lower extremity lymphedema: the generation of a novel lymphedema severity staging system using dermal backflow patterns. Plast Reconstr Surg 2011;127:1979-86.

[27] Kwon S, Sevick-Muraca EM. Noninvasive quantitative imaging of lymph function in mice. Lymphat Res Biol 2007;5:219-31.

[28] Buettner M, Bode U. Lymph node dissection - understanding the immunological function of lymph nodes. Clin Exp Immunol 2012;169:205-12.

[29] Dixon JB. Lymphatic lipid transport: sewer or subway? Trends Endocrinol Metab 2010;21:480-7.

[30] Blum KS, Proulx ST, Luciani P, Leroux JC, Detmar M. Dynamics of lymphatic regeneration and flow patterns after lymph node dissection. Breast Cancer Res Treat 2013; 139:81-6.

[31] Shao L, Mori S, Yagishita Y, Okuno T, Hatakeyama Y, Sato T, et al. Lymphatic mapping of mice with systemic lymphoproliferative disorder: usefulness as an inter-lymph node metastasis model of cancer. J Immunol Methods 2013;389: 69-78.

[32] Huggenberger R, Ullmann S, Proulx ST, Pytowski B, Alitalo K, Detmar M. Stimulation of lymphangiogenesis via VEGFR-3 inhibits chronic skin inflammation. J Exp Med 2010;207:2255-69.

[33] Kobayashi Y. The regulatory role of nitric oxide in proinflammatory cytokine expression during the induction and resolution of inflammation. J Leukoc Biol 2010;88: $1157-62$.

[34] Boardman KC, Swartz MA. Interstitial flow as a guide for lymphangiogenesis. Circ Res 2003;92:801-8.

[35] Miyashita K, Itoh $\mathrm{H}$, Sawada N, Fukunaga $\mathrm{Y}$, Sone $\mathrm{M}$, Yamahara $\mathrm{K}$, et al. Adrenomedullin provokes endothelial Akt activation and promotes vascular regeneration both in vitro and in vivo. FEBS Lett 2003;544:86-92.

[36] Maegawa J, Yabuki Y, Tomoeda H, Hosono M, Yasumura K. Outcomes of lymphaticovenous side-to-end anastomosis in peripheral lymphedema. J Vasc Surg 2012;55:753-60

[37] Demirtas Y, Ozturk N, Yapici O, Topalan M. Supermicrosurgical lymphaticovenular anastomosis and lymphaticovenous implantation for treatment of unilateral lower extremity lymphedema. Microsurgery 2009;29:609-18.

[38] Tammela T, Alitalo K. Lymphangiogenesis: molecular mechanisms and future promise. Cell 2010;140:460-76. 